\title{
Effects of Antidepressants, but not Psychopathology, on Cardiac Sympathetic Control: A Longitudinal Study
}

\author{
Carmilla MM Licht*,', Brenda WJH Penninx ${ }^{1,2,3}$ and Eco JC de Geus ${ }^{4}$ \\ 'Department of Psychiatry/EMGO Institute for Health and Care Research, VU University Medical Center, Amsterdam, The Netherlands; \\ ${ }^{2}$ Department of Psychiatry, Leiden University Medical Center, Leiden, The Netherlands; ${ }^{3}$ Department of Psychiatry, Groningen University Medical \\ Center, Groningen, The Netherlands; ${ }^{4}$ Department of Biological Psychology, VU University, Amsterdam, The Netherlands
}

\begin{abstract}
Increased sympathetic activity has been hypothesized to have a role in the elevated somatic disease risk in persons with depressive or anxiety disorders. However, it remains unclear whether increased sympathetic activity reflects a direct effect of anxiety or depression or an indirect effect of antidepressant medication. The aim of this study was to test longitudinally whether cardiac sympathetic control, measured by pre-ejection period (PEP), was increased by depression/anxiety status and by antidepressant use. Cross-sectional and longitudinal data were from a depression and anxiety cohort: the Netherlands Study of Depression and Anxiety (NESDA). Baseline data of 2838 NESDA subjects (mean age 41.7 years, 66.7\% female) and 2-year follow-up data of 2226 subjects were available for analyses. Included were subjects with and without depressive/anxiety disorders, using or not using different antidepressants at baseline or followup. The PEP was measured non-invasively by $1.5 \mathrm{~h}$ of ambulatory impedance cardiography. Cross-sectional analyses compared PEP across psychopathology and antidepressant groups. Longitudinal analyses compared 2-year changes in PEP in relation to changes in psychopathology and antidepressant use. Cross-sectional analyses showed that antidepressant-naïve depressive/anxious subjects had comparable PEP as controls, whereas subjects using tricyclic (TCA) or combined serotonergic/noradrenergic antidepressants (SNRI) had significantly shorter PEP compared with controls. In contrast, subjects using selective serotonin re-uptake inhibitors (SSRIs) had longer PEP than controls. Longitudinal results confirmed these findings: compared with 2-year change in PEP in continuous non-users ( +2 ms), subjects who started TCA or SNRI treatment showed significantly shortened PEP $(-$ I I ms, $p=0.005$ and $p<0.00$ I), whereas subjects who started SSRI treatment showed significant prolongation of PEP ( $9 \mathrm{~ms}, p=0.002$ ). Reversed findings were observed among those who stopped antidepressant use. These findings suggest that depressive and anxiety disorders are not associated with increased cardiac sympathetic control. However, results pose that TCA and SNRI use increases sympathetic control, whereas SSRI use decreases sympathetic control.

Neuropsychopharmacology (2012) 37, 2487-2495; doi:I0.1038/npp.2012.107; published online 4 July 2012
\end{abstract}

Keywords: sympathetic nervous system; major depressive disorder; pre-ejection period; antidepressants; anxiety disorder

\section{INTRODUCTION}

Increased activity of the sympathetic nervous system (SNS) may have an important role in the increased risk for cardiovascular and metabolic disease in patients with depressive and anxiety disorders (Glassman, 2008; Penninx et al, 2001; Eaker et al, 2005; Nicholson et al, 2006; Esler et al, 2006; Flaa et al, 2008a, b; Masuo et al, 2005, 2010). Various studies reported increased sympathetic activity in depressed and anxious subjects compared with healthy controls, measured by different indices like spillover of norepinephrine

*Correspondence: Dr CMM Licht, Department of Psychiatry/EMGO Institute for Health and Care Research, VU University Medical Center, A) Ernststraat 1 187, Amsterdam 108 | HL, The Netherlands,

Tel: + 3 I (0)20788 4664, Fax: + 31 (0)20 7885664 ,

E-mail: C.Licht@vumc.nl or C.Licht@ggzingeest.nl

Received 19 January 2012; revised 16 May 2012; accepted 31 May 2012
(NE) and epinephrine (EPI), skin conductance responses, QT interval variability (QTvi), or the pre-ejection period (PEP) (Light et al, 1998; Esler et al, 1982; Guinjoan et al, 1995; Gold et al, 2005; Koschke et al, 2009; Barton et al, 2007). However, other studies reported no association between psychopathology and SNS activity or reported decreased SNS activity in subjects with depressive or anxiety disorders (Wilkinson et al, 1998; Esler et al, 2004; Roth et al, 2008; Ahrens et al, 2008), so findings remain inconclusive. A first major source of confounding in studies comparing SNS activity between depressed/anxious subjects and controls might be the different SNS indices used, with some measuring true NE release whereas others measure organ responsivity, which may also be influence by changes in clearance, re-uptake, or adrenoceptor sensitivity. A second major source of confounding might be the high prevalence of antidepressants in the patient groups.

The potential for confounding of autonomic effects by antidepressants was clearly demonstrated in our own recent 
research on the association between major depressive disorder (MDD) and anxiety disorders and cardiac vagal activity and blood pressure (Licht et al, 2008, 2009b, c), where we found that especially the use of tricyclic antidepressants (TCAs) and serotonergic and noradrenergic reuptake inhibitors (SNRIs) were associated with decreased vagal activity and increased blood pressure. We confirmed these findings with longitudinal evidence indicating that starting the intake of TCAs and SNRIs caused a decrease in vagal activity paired to an increase in heart rate (HR) (Licht et al, 2010). These findings suggest that TCAs and SNRIs increase sympathetic control of the heart. Remarkably, starting selective serotonin re-uptake inhibitor (SSRI) use was found to cause a decrease in HR in spite of lowered vagal activity (Licht et al, 2010), which suggests that SSRI use leads to a decrease in cardiac sympathetic control. Similar results were found by other research groups: Roth et al (1988) and Koschke et al (2009) reported increases in HR after administration of imipramine (a TCA) and venlafaxine and duloxetine (SNRIs). Shores et al (2001) and Barton et al (2007) found decreases in plasma NE, after SSRI use. These patterns of findings suggest differential effects of different antidepressants (Dawood et al, 2009; Licht et al, 2009a; Koschke et al, 2009).

Here, we examine the (longitudinal) association between cardiac sympathetic activity and depression and/or anxiety disorder, taking effects of different antidepressants into account. To measure cardiac sympathetic activity, we use non-invasive thoracic impedance cardiography to derive the PEP as the time interval between the onset of ventricular depolarization and the opening of the semilunar valves (Sherwood et al, 1990). Changes in PEP reliably index changes in $\beta$-adrenergic inotropic drive to the left ventricle as shown in laboratory studies manipulating $\beta$-adrenergic tone by EPI infusion (Mezzacappa et al, 1999; Schachinger et al, 2001; Svedenhag et al, 1986), amyl nitrite inhalation (Nelesen et al, 1999), adrenoceptor blockade (Harris et al, 1967; Schachinger et al, 2001; Winzer et al, 1999; Cacioppo et al, 1994), exercise (Krzeminski et al, 2000; Miyamoto et al, 1983; Smith et al, 1989), or emotional stress (Berntson et al, 1994; Newlin and Levenson, 1979; Sherwood et al, 1986). PEP is an indirect measure of cardiac sympathetic activity as the sympathetic effects on the left ventricle are not just determined by changes in cardiac NE release but also by adrenoceptor status and circulating catecholamines. Throughout the text, we therefore refer to PEP as a measure of cardiac sympathetic control, rather than activity. In contrast to cardiac NE spillover (Barton et al, 2007; Esler et al, 1982, 2004), PEP is a measure that can be obtained in large samples of patients and controls.

We measured PEP in subjects with and without depressive and/or anxiety disorders, using or not using an antidepressant, at the baseline assessment and 2-year follow-up of a large cohort study. We expect shorter PEP (reflecting increased cardiac sympathetic activity) in subjects with anxiety and/or depression, signalling higher cardiac sympathetic control, which normalizes when patients remit at follow-up. In addition, in view of our previous results, we expect to find a shorter PEP in subjects taking TCAs and SNRIs, but a longer PEP in SSRI users. To determine causality more closely, we will test whether changes in psychopathology/antidepressant status from baseline to follow-up are reflected in parallel changes in cardiac sympathetic control.

\section{SUBJECTS AND METHODS}

\section{Subjects}

Subjects participating in this study came from the Netherlands Study of Depression and Anxiety (NESDA), an ongoing longitudinal cohort study conducted among 2981 subjects (18-65 years, $95.2 \%$ of North European ancestry) to examine the long-term course of depression and anxiety disorders. The rationale, methods, and recruitment strategy have been described elsewhere (Penninx et al, 2008). The NESDA sample consists of persons without depression and anxiety disorders and persons with a (remitted or current) diagnosis of depressive or anxiety disorder. In order to represent various settings and stages of psychopathology, depressed or anxious subjects were recruited at three different locations in the Netherlands in different settings: general community, through a screening procedure in primary care, and via mental health-care organizations. The baseline assessment lasted on average $4 \mathrm{~h}$ and included assessment of demographic and health and lifestyle characteristics, a standardized diagnostic psychiatric interview and a medical assessment. The presence of a depressive (MDD or dysthymia) and/or anxiety disorder (social phobia, generalized anxiety disorder, panic disorder with or without agoraphobia, and agoraphobia only) was ascertained using the lifetime version of the CIDI psychiatric interview (WHO version 2.1). The CIDI establishes diagnoses according to the DSM-IV criteria (American Psychiatric Association, 2001) and has shown high interrater and test-retest reliability and high validity for depressive and anxiety disorders (Wittchen, 1994). In addition, the severity of anxiety was measured among all subjects using the Beck Anxiety Inventory (BAI; Steer et al, 1995) and the severity of depression with the 30-item Inventory of Depressive Symptoms self-report version (Rush et al, 1996). The research protocol was approved by the ethical committee of participating universities and all respondents provided written informed consent.

Two years after baseline assessment, a face-to-face followup assessment was conducted with a response of $87.1 \%$ (2596 of the 2981 respondents participated). Non-responders were younger, more often of non-North European ancestry, less educated, and more often had MDD (Lamers et al, 2012).

\section{Patterns of (Change in) Psychopathology and Antidepressant Use}

First, for cross-sectional analyses, the sample was divided into groups based on psychiatric status and the use of antidepressants. The use of different antidepressants at baseline and at follow-up was determined based on drug container inspection of all drugs used in the month before assessment and classified according to the Anatomical Therapeutic Chemical (ATC) classification (World Health Organization Collaborating Centre for Drug Statistics Methodology, 2010). Use of antidepressants was considered present when taken for at least 1 month and $50 \%$ of the 
time, and included TCAs (ATC-code N06AA), noradrenergic and serotonergic working antidepressants (SNRIs, ATCcode N06AF/N06AX) and SSRIs (ATC-code N06AB). In this way, a seven-group variable was created for cross-sectional analyses for baseline as well as with 2-year follow-up. The first five groups comprises antidepressant-naïve individuals: a control group without lifetime diagnoses, a group with a lifetime but no current depressive and/or anxiety disorder ( $>6$ month ago), a group with a current (6-month recency) anxiety disorder, a current depressive group, and a group with current comorbid depressive and anxiety disorders. The final three groups comprises those taking a TCA, SNRI, or SSRI. At baseline, 143 subjects had missing physiological data, at follow-up 370 (60 subjects at both time points). Therefore, at baseline and at the 2-year followup 2838 and 2226 persons, respectively, fulfilled one of the group criteria.

Second, patterns of change in depressive and anxiety disorder status were defined to examine 2-year changes in sympathetic control in these groups. To investigate the pure effects of incidence or remission of depressive or anxiety disorders, persistence, remission, or new onset of depressive and anxiety disorders were determined categorizing antidepressant-naïve subjects into four disorder groups: (a) persistent controls, no (lifetime) diagnoses at baseline and follow-up, (b) persistent patients, a current depressive and/or anxiety diagnoses at baseline and follow-up, (c) remitted patients, subjects with a current diagnosis at baseline and no current diagnosis at follow-up, and (d) new patients, no diagnosis at baseline and current diagnosis at follow-up.

Patterns of change in antidepressant use were determined by categorizing subjects based on antidepressant status over 2 years as: (1) persistent non-users, consisting of subjects who did not use any antidepressant at baseline and follow-up, (2) persistent users, defined as use of a specific antidepressant at both baseline and follow-up, (3) new users of an antidepressant, which was defined as no use at baseline and the use of an antidepressant at follow-up, (4) subjects that stopped using antidepressants, defined as using an antidepressant at baseline and none at follow-up, and (5) subjects that switched from using one type of antidepressant at baseline to another type of antidepressant at follow-up (SSRI $\rightarrow$ SNRI, SNRI $\rightarrow$ SSRI, and so on).

\section{Measurements}

Pre-ejection period. During the baseline as well as 2-year follow-up visit to the research centers, NESDA subjects were wearing the Vrije Universiteit Ambulatory Monitoring System (VU-AMS). The VU-AMS is a light-weight device that unobtrusively records the electrocardiogram (ECG) and changes in thorax impedance (dZ) from six surface electrodes placed at the chest and back of the subjects (de Geus et al, 1995; Willemsen et al, 1996). From the ECG, the $\mathrm{R}$-wave times were extracted from which, after visual inspection of the inter-beat-interval time series, HR was computed. The PEP was extracted from the dZ/dt (ICG) signal that was ensemble averaged across 1-min periods time-locked to the R waves in the ECG. Three time points can be scored in ICG ensemble averages: the upstroke or B point, the $\mathrm{dZ} / \mathrm{dt}(\mathrm{min})$ point, and the incisura or $\mathrm{X}$ point.
The PEP is defined as the interval from the upstroke of the ICG (B point), which is the onset of the left ventricular electrical activity to the $\mathrm{dZ} / \mathrm{dt}(\mathrm{min})$ point that indicates the beginning of blood ejection through the aortic valve.

Postural changes can cause changes in PEP that are partially independent of changes in sympathetic control (Houtveen et al, 2005). To avoid confounding of PEP by posture, three periods were identified in the total recording period in which subjects did not change posture and were quietly sitting for a prolonged period. Movement registration through vertical accelerometry was used to excise fragments of the recording where subjects were physically active (eg, bathroom visit). There were three assessment parts in which subjects did not change posture and were sitting for a prolonged period at both baseline and followup: interview session 1 (sitting, baseline: $38.2 \pm 12.7 \mathrm{~min}$, follow-up: $46.0 \pm 25.9 \mathrm{~min}$ ), interview session 2 (sitting, baseline: $35.6 \pm 12.7 \mathrm{~min}$, follow-up: $32.5 \pm 12.0 \mathrm{~min}$ ), and a non-stressful computer task (sitting, baseline: $16.2 \pm$ $4.0 \mathrm{~min}$, follow-up: $15.2 \pm 3.4 \mathrm{~min}$ ). These three assessment parts were used in the final analyses. A single large-scale ensemble average was then created for the three interview parts and the relevant time point (B point) were scored in each of these large-scale ensembles by a single rater (CL). Ensembled ICGs that showed irregularities or had ambiguous B point were not considered valid and were rejected and removed from further processing during visual inspection (Eckberg, 2003; Grossman et al, 1990). A second independent rater (EdG) re-scored 600 randomly chosen subjects from baseline and follow-up yielding an inter-rater reliability for PEP scoring of 0.84 .

Exploratory mixed model analyses revealed that differences across antidepressants and psychopathology groups were very comparable in the three different interview conditions, at baseline as well as at follow-up. Therefore, data during the computer task and interview parts were collapsed to create one single PEP value per subject, for the baseline (averaged over $90.2 \pm 23 \mathrm{~min}$ time) and 2-year follow-up assessment (averaged over $93.6 \pm 36 \mathrm{~min}$ time).

Covariates. Sociodemographics included age, sex, and education in years. In addition, various health indicators (at both time points) were considered as covariates because these have been linked with depressive/anxiety disorder and SNS activity. Body mass index (BMI) was determined as measured weight in kilograms divided by the square of the measured height in meters. Physical activity was measured using the International Physical Activity Questionnaire (Booth, 2000) and expressed in MET-minutes per week (the multiple of one's resting metabolic rate times minutes of physical activity per week). Smoking status was defined as number of smokes a day. Similarly, alcohol use was defined as number of alcoholic consumptions a day. Selfreports of the presence of heart disease were used for ascertainment of cardiovascular diseases (CVDs; including coronary disease, cardiac arrhythmia, angina, heart failure, and myocardial infarction), only when confirmed with the use of specific medication. Dichotomous variables for the use of medication were computed, scoring 'yes' if subjects frequently (daily or $>50 \%$ of the time) used a medication. For the confirmation of CVD, cardiac medication (starting with ATC-code C01DA, and C08) was used. Self-reports 
were used for ascertainment of the presence of other chronic conditions (epilepsy, diabetes, osteoarthritis, stroke, cancer, chronic lung disease, thyroid disease, liver disease, chronic fatigue syndrome, intestinal disorders, and ulcer). Furthermore, it was determined whether subjects were using $\beta$-blocking agents (ATC code C07) or other cardiac medication (ATC-codes C01 (minus C01DA), C02, C03, C04, C05, and C09).

Independent of cardiac sympathetic drive, the PEP can be prolonged by increases in afterload or decreases in preload. No non-invasive measures of between-subject differences in preload that can be applied in large samples are currently available (Norton, 2001). To account for between-subject differences in afterload, mean arterial blood pressure (MAP) was used as a proxy for mean aortic pressure. Systolic (SBP) and diastolic blood pressure (DBP) were recorded in a supine position by two repeated measurements using the OMRON M4 IntelliSense (HEM-752A, Omron Healthcare, Bannockburn, IL). MAP was calculated by $(\mathrm{SBP}+2 \times \mathrm{DBP}) /$ 3. In a separate adjustment step, we checked whether results were further influenced by taking individual differences in HR (extracted from the ECG inter-beat-interval time series) and MAP into account (Weissler et al, 1968; Wolf et al, 1978). Finally, in order to examine whether severity of symptomatology further impacted on found associations, analyses were additionally corrected for depression and anxiety severity using the IDS and BAI scores (Rush et al, 1996; Steer et al, 1995).

\section{Statistical Analyses}

Data was analyzed using SPSS 18.0. Characteristics at baseline and follow-up assessment were compared using unpaired $t$-tests and $\chi^{2}$ statistics. Cross-sectional analyses of variance at both time points were conducted to compare PEP across the controls, the unmedicated depressed and/or anxious subjects, and the depressed and/or anxious subjects using different antidepressants (eight groups). These analyses were repeated with consideration of covariates. Subsequently, effect sizes were calculated with Cohen's $d$ (1988) defined as the difference in the mean PEP between groups, divided by the pooled standard deviation of these groups. For longitudinal analyses, adjusted linear mixed model analyses were conducted for the 2-year change in PEP across psychopathology (persistent control or new, remitted or persistent diagnosis) and antidepressant groups (continued (non)use, new or stopped use of antidepressants). Since covariates can change within persons over a period of 2 years and these changes might influence PEP, we took possible changes in covariates into account when analyzing the longitudinal data by using linear mixed model analyses with time varying covariates.

\section{RESULTS}

Table 1 shows and compares the main characteristics of the samples at baseline $(n=2838)$ and follow-up $(n=2226)$. Compared with the baseline sample, subjects were more physically active, had a higher BMI, smoked less often, and used more cardiac medication (other than $\beta$-blockers) at follow-up. At follow-up, subjects had less current but more remitted depression or anxiety diagnoses and fewer subjects used a SSRI. HR was slightly higher and MAP slightly lower in the follow-up sample. PEP did not significantly differ between the baseline and follow-up sample.

Table 2 shows the results of ANCOVA analyses conducted for both time points. The PEP of the psychopathology and antidepressant groups was compared with the PEP of the control group, first uncorrected and then corrected for age, sex, education, lifestyle, and health factors. In both unadjusted (data not shown) and adjusted analyses (see Table 2), no differences in PEP were found between the unmedicated patient groups and the controls. However, consistently across time points, PEP was significantly shorter in TCA and SNRI users ( $p$-values $\leqslant 0.001$ and $d$-values $0.296-1.248)$ and significantly longer in SSRI users ( $p$-values $<0.001$ and $d$-values $0.444-0.410$ for baseline and follow-up, respectively). Although $\mathrm{HR}$ and MAP also differed between groups, additional adjustment for HR and MAP did not further influence the results for the comparison between (un)medicated patients and controls. In spite of the potential effects of these agents on PEP, repetition of all analyses excluding users of $\beta$-blocking agents yielded similar results. Table 2 indicates substantial differences in IDS and BAI scores between controls and (un)medicated patients, therefore additional analyses were performed investigating the effects of severity. When PEP was compared between controls and unmedicated patients with (at least) similar IDS and BAI scores as medicated patients, still no differences were found. This finding was confirmed by the absence of significant correlations between the pre-ejection with the IDS and BAI score ( $r=0.033, p=0.13$ and $r=0.028, p=0.20$, respectively). Additional analyses were performed to compare PEPs between different anxiety disorders, but no differences were found.

Longitudinal fully adjusted mixed model analysis on the four different psychiatric groups (not using antidepressants) showed that persons who developed a new diagnosis, persons with a persistent diagnosis, or persons who remitted from a current diagnosis did not differ in 2-year change in PEP compared with persistent healthy controls (group $\times$ time $\mathrm{F}=1.192, \mathrm{df}=3, p=0.31$ ). This analysis further confirms the lack of association between the presence of (antidepressant-naïve) depressive or anxiety disorders with PEP.

Figure 1 shows the results of the fully adjusted linear mixed model analysis on 2-year change in PEP across the 12 different antidepressant groups. The overall group $\times$ time interaction was significant $(\mathrm{F}=16.470, \mathrm{df}=11, p<0.001)$, indicating that changes in PEP over time were significantly different across antidepressant groups, taking into account all covariates. The 2-year change in PEP among persistent non-users was only minor: $1.9 \mathrm{~ms}(1.6 \%)$. Subjects who started using a TCA or SNRI, showed a prominent shortening in PEP: new TCA users had a 2-year PEP shortening of 9.8\% (compared with persistent non-users: $p=0.005$, effect size $d=0.783)$ and new SNRI users of $9.1 \%(p<0.001$, $d=0.766)$. Subjects switching from an SSRI to an SNRI led to a shortening in PEP $(-19.5 \%, p<0.001, d=1.882)$, and a further shortening in the PEP was observed in continuous users of TCAs at baseline and follow-up $(-9.4 \%, p<0.001$, $d=0.560$ ). Consistent with these observations, subjects that 
Table I Sample Characteristics

\begin{tabular}{|c|c|c|c|c|}
\hline & Baseline $(N=2838)$ & 2-year FU $(N=2226)$ & $\Delta$ & $p^{a}$ \\
\hline \multicolumn{5}{|l|}{ Sociodemographics } \\
\hline Age, years (SD) & $41.7(13.1)$ & $44.2(13.2)$ & 2.5 & $<0.001$ \\
\hline Female \% $(N)$ & $66.7(1892)$ & $66.4(1477)$ & -0.3 & 0.81 \\
\hline Education, years (SD) & $2.2(3.3)$ & $12.5(3.3)$ & 0.3 & 0.001 \\
\hline Physical activity, I000 MET min/week (SD) & $3.7(3.0)$ & $4.1(3.3)$ & 0.4 & $<0.001$ \\
\hline Body mass index (SD) & $25.5(5.0)$ & $25.8(4.9)$ & 0.3 & 0.03 \\
\hline Smoking, number/day (SD) & $5.0(8.7)$ & $4.2(7.8)$ & -0.8 & $<0.001$ \\
\hline Non-smoker, \% (n) & $28.3(802)$ & $30.9(688)$ & 2.6 & 0.04 \\
\hline Former smoker, \% ( $n$ ) & $33.3(944)$ & $34.7(773)$ & 1.3 & 0.28 \\
\hline Heavy drinker, \% (n) & $11.4(323)$ & $10.5(234)$ & -0.9 & 0.34 \\
\hline Use $\beta$-blockers, \% (n) & $7.8(220)$ & $8.4(188)$ & 0.6 & 0.37 \\
\hline Use other heart medication, \% ( $n$ ) & $10.7(304)$ & 13.3 (296) & 2.6 & 0.005 \\
\hline Cardiovascular disease, \% (n) & $7.4(209)$ & $8.5(189)$ & 1.1 & 0.14 \\
\hline Number of chronic diseases, mean (SD) & $0.92(1.1)$ & $0.94(1.1)$ & 0.02 & 0.52 \\
\hline Mean arterial pressure, $\mathrm{mmHg}(\mathrm{SD})$ & $98.7(12.4)$ & $96.5(11.8)$ & -2.2 & $<0.001$ \\
\hline Heart rate, b.p.m. (SD) & $72.0(9.6)$ & $72.7(9.7)$ & 0.7 & 0.01 \\
\hline \multicolumn{5}{|l|}{ Psychopathological factors } \\
\hline Control, \% (n) & $21.9(621)$ & $20.7(460)$ & -0.5 & 0.63 \\
\hline Current comorbid diagnosis, \% (n) & $44.7(726)$ & $38.2(323)$ & -6.5 & 0.002 \\
\hline TCA use, $\%(n)$ & $2.6(75)$ & $2.8(63)$ & 0.2 & 0.66 \\
\hline SNRI use, \% (n) & $5.7(162)$ & $5.7(126)$ & 0.0 & 0.95 \\
\hline SSRI use, \% (n) & I7.I (484) & I $3.7(305)$ & -3.4 & 0.001 \\
\hline \multicolumn{5}{|l|}{ Cardiac autonomic control } \\
\hline Pre-ejection period, ms (SD) & | $19.3(\mid 8.3)$ & $119.4(17.5)$ & 0.1 & 0.84 \\
\hline
\end{tabular}

Abbreviations: FU, follow-up; MET, multiple of the resting metabolic rate.

${ }^{a}$ Comparison of baseline and FU values using $t$-test (continuous variables) and $\chi^{2}$-square statistics (dichotomous/categorical variable).

stopped taking a TCA or SNRI showed a lengthening in PEP over time $(15.6 \%, p=0.006, d=1.056$ and $6.8 \%, p=0.02$, $d=0.596$, respectively). In contrast to the PEP shortening effect of TCA and SNRIs, new SSRI users had a 7.3\% longer PEP at the 2-year follow-up $(p<0.001, d=0.542)$. Consistent with this, the PEP of SSRI users that stopped taking medication had significantly shortened $(-9.9 \%, p<0.001$, $d=0.979$ ).

Adding the IDS and BAI scores of both time points as covariates did not change any of the above-mentioned results indicating that observed medication effects were independent of potential differences in severity of depressive and anxiety symptoms.

\section{DISCUSSION}

This large-scale cohort study showed that cardiac sympathetic control, as measured by the PEP, is increased in subjects using TCAs or SNRIs. Users of SSRIs had a 
Table 2 The Adjusted ${ }^{a}$ PEP (ms) per Psychiatric and Medication Group, Cross-Sectional for Baseline and Follow-Up

\begin{tabular}{|c|c|c|c|c|c|c|c|c|}
\hline & $\mathbf{N}$ & IDS & BAI & MAP & HR & Mean PEP (SE) ${ }^{\mathbf{a}}$ & $p$ & Effect size \\
\hline \multicolumn{9}{|l|}{ Baseline } \\
\hline Not using antidepressants & & & & & & & & \\
\hline Control & 597 & 8.1 & 3.9 & $98.7(12.6)$ & $72.0(8.8)$ & $120.3(0.7)$ & $\operatorname{Ref}^{b}$ & $\operatorname{Ref}^{b}$ \\
\hline Remitted anxiety or depressive & 501 & 13.4 & 6.6 & $98.1(12.0)$ & $71.3(9.9)$ & I $19.2(0.8)$ & 0.29 & 0.063 \\
\hline Current anxiety disorder & 358 & 21.6 & 14.3 & $98.6(13.1)$ & $71.7(9.4)$ & I $19.3(0.9)$ & 0.35 & 0.063 \\
\hline Current anxiety and depressive disorder & 402 & 33.1 & 20.0 & $98.2(12.8)$ & $71.7(9.5)$ & | $20.7(0.8)$ & 0.72 & 0.023 \\
\hline \multicolumn{9}{|l|}{ Using antidepressants } \\
\hline TCA user & 75 & 30.2 & 19.3 & I05.8( ( 3.2) & $81.1(11.6)$ & $109.4(2.0)$ & $<0.001$ & 0.639 \\
\hline SNRI user & 160 & 32.3 & 17.8 & $100.9(11.5)$ & $73.7(9.3)$ & I I5.3 (।.3) & 0.001 & 0.296 \\
\hline SSRI user & 466 & 30.1 & 17.8 & $98.6(12.0)$ & $70.8(9.6)$ & I $27.9(0.8)$ & $<0.001$ & 0.444 \\
\hline Control & 456 & 6.2 & 3.1 & $97.1(12.4)$ & $73.0(9.2)$ & $120.6(0.8)$ & $\operatorname{Ref}^{b}$ & $\operatorname{Ref}^{b}$ \\
\hline Remitted anxiety or depressive & 734 & 12.1 & 6.2 & $95.6(11.6)$ & $72.5(9.5)$ & । $18.8(0.6)$ & 0.23 & 0.104 \\
\hline Current anxiety disorder & 219 & 19.0 & 12.3 & $96.0(11.6)$ & $71.5(10.7)$ & $120.8(1.1)$ & 0.82 & 0.012 \\
\hline Current depressive disorder & 147 & 21.6 & 10.7 & $96.5(12.6)$ & $71.1(7.5)$ & $120.6(1.3)$ & 0.94 & 0.001 \\
\hline Current anxiety and depressive disorder & 186 & 30.7 & 18.2 & $96.3(11.0)$ & $71.5(9.8)$ & $120.6(1.2)$ & 0.89 & 0.006 \\
\hline \multicolumn{9}{|l|}{ Using antidepressants } \\
\hline TCA user & 63 & 22.4 & 13.1 & $102.5(\mid 1.0)$ & $82.4(10.7)$ & $99.9(2.1)$ & $<0.001$ & 1.248 \\
\hline SNRI user & 124 & 23.7 & 12.9 & $100.2(\mid 1.8)$ & $76.9(\mid 1.1)$ & $108.3(1.5)$ & $<0.001$ & 0.746 \\
\hline \multirow[t]{2}{*}{ SSRI user } & 297 & 21.1 & 11.8 & $95.6(\mid 1.1)$ & $71.0(9.0)$ & $127.3(0.9)$ & $<0.001$ & 0.410 \\
\hline & 2226 & & & & & & & \\
\hline
\end{tabular}

Abbreviations: AD, antidepressant; BAI, Beck anxiety inventory; IDS, inventory of depressive symptoms; PEP, pre-ejection period; SNRI, serotonergic and noradrenergic working antidepressant; SSRI, selective serotonin re-uptake inhibitor; TCA, tricyclic antidepressant.

${ }^{a}$ Analyses were adjusted for age, sex and education, BMI, physical activity, smoking, alcohol use, use of $\beta$-blocking agents, use of other heart medication, chronic disease, and CVD.

${ }^{b}$ Control is the reference group. All p-values and effect sizes are for comparison of the group in that specific line and control subjects.

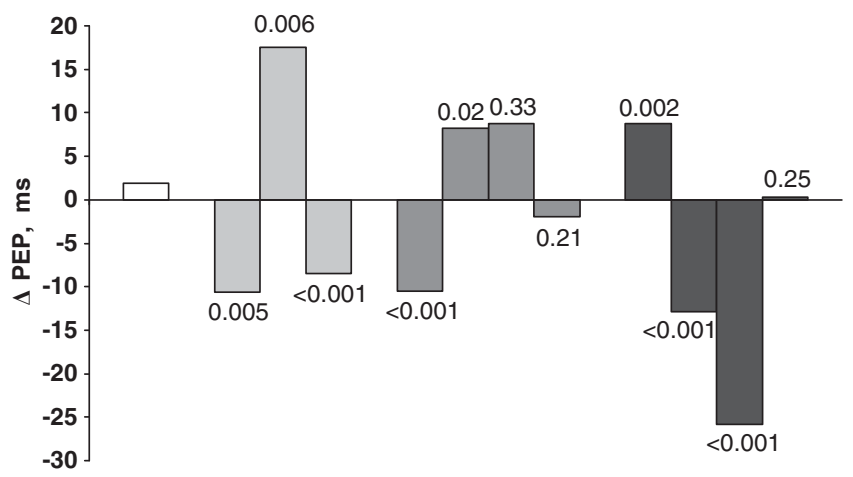

AD baseline: no AD follow-up: no

no TCA TCA no SNRI SNRI SNRI TCA no TCA SNRI no SNRI SNRI

$\begin{array}{lllllll}11 & 10 & 40 & 23 & 34 & 10 & 68\end{array}$ no SSRI SSRI SSRI SSRI nO SNRI SSRI $\begin{array}{llll}73 & 121 & 25 & 192\end{array}$

Figure I Mean adjusted* change in pre-ejection period (ms) from baseline to 2-year follow-up for different antidepressant groups. *Adjusted for age, sex and education, BMI, physical activity, smoking, alcohol use, use of $\beta$-blocking agents, use of other heart medication, chronic disease, and CVD. The $p$-values are for changes in PEP in the indicated groups in comparison with the 1500 persistent non-users ('no-no').

significantly longer PEP compared with non-medicated subjects, indicative of decreased cardiac sympathetic control. The presence of depressive or (different) anxiety disorders itself was not related to cardiac sympathetic control, nor was severity of the disorder. Results were confirmed and consistent in cross-sectional and longitudinal analyses.

Our findings are in agreement with our previous findings on HR and blood pressure. Similar HR and MAP was found in the unmedicated patients compared with healthy controls. TCA and SNRI users showed increased values of HR and MAP, whereas the SSRI users had a similar or lower HR and MAP. Of the two previous studies comparing PEP between depressed and healthy controls, one also failed to find systematic evidence for PEP differences between depressive and healthy persons, whereas the other found a significant decreased PEP in depressed compared with healthy controls (Bruno et al, 1983; Light et al, 1998). A reason for the different results could be the difference in sample size and composition. Our study sample had a much larger sample size than previous studies and, through the recruitment strategy in both general practice as well as specialized 
mental health-care practice, reflects the general population of depressed and anxiety patients. Several reports using different SNS indices also found increased sympathetic activity in depressed or anxious subjects (Esler et al, 1982; Gold et al, 2005; Guinjoan et al, 1995; Light et al, 1998; Koschke et al, 2009). These previous reports focused on general sympathetic activity, whereas we measured sympathetic control more narrowly by its effects on cardiac contractility. Guinjoan et al (1995) described a higher sympathetic skin response in 18 melancholically depressed patients compared with 18 healthy controls. Gold et al (2005), reported higher plasma NE levels in 10 subjects with severe melancholic depression than in 12 healthy controls. Light et al (1998) also found higher plasma NE levels in high-symptom group compared with a low-symptom group. Higher plasma catecholamine levels could reflect either an increase in catecholamine production or a decrease in the clearance of catecholamines between patients and controls. To resolve this, radiotracer techniques can be used. Esler et al (1982) detected greater SNS activity by whole body NE spillover in 11 depressed outpatients compared with 17 healthy controls, arguing in favor of a true increase in sympathetic activity in the nerves in depressed patients. This was partly replicated by later spillover studies that only detected high sympathetic nervous activity, including in the sympathetic outflow to the heart, in the subset of MDD patients comorbid for panic disorder (Barton et al, 2007). It is important to note that an increase in cardiac sympathetic nerve activity is not incompatible with the absence of effects on cardiac contractility as reported here. Chronic exposure to high levels of NE may have led to a downregulation of cardiac $\beta$-receptors in the depressed or anxious patients. A similar state of events is seen in patients with left heart failure, where the ejection fraction, another measure of contractility, is strongly reduced in the presence of increased sympathetic drive (Eisenhofer et al, 1996; Esler et al, 1982). Studies that measure the cardiac adrenoceptor status of depressive and anxiety patients are needed to test this.

Our results suggest a potential lowering effect of SSRIs on cardiac sympathetic control, whereas TCAs and SNRIs seem to increase cardiac sympathetic control. Differential effects of SNRI and SSRI were also seen by Koschke et al (2009) and findings are consistent with most previous studies on the effects of these drugs (Howell et al, 2007; Barton et al, 2007; Shores et al, 2001; Roth et al, 1988; Veith et al, 1983; Vincent et al, 2004; Dawood et al, 2009; Licht et al, 2009a; Koschke et al, 2009). TCAs and SNRIs both work through inhibition of NE in the synaptic cleft or by blocking its clearance. Veith et al (1994) showed that, using plasma NE kinetic measurements, desipramine acutely (2 days) suppressed plasma NE appearance (suggesting suppression of total body SNS activity) followed by a return to baseline levels after 4 weeks. The elevation of plasma NE at that time point was due to decreased clearance and this is likely to be a major reason why other studies of TCA effects have shown elevation of circulating NE.

Increased circulating NE levels likely also increase NE concentration in the sinoatrial node (Shimizu et al, 2010) and the left ventricle, thereby directly affecting contractility and HR. In contrast, SSRIs do not exert an effect on circulating NE but instead reduce the firing rate in the noradrenergic locus coeruleus (Grant and Weiss, 2001), which is part of the brainstem circuitry generating cardiac sympathetic activity (Elam et al, 1984, 1986; Svensson, 1987). Furthermore, serotonergic inhibitory receptors are present in ventral medulla (Helke et al, 1997), which is part of the same regulatory circuitry of sympathetic activity (Nalivaiko, 2006). The significant differences between the effects of these classes of medication on cardiac sympathetic effects in our study appear to have a plausible biological basis.

A study limitation has to be mentioned. Activity of the cardiac sympathetic nerves was derived indirectly by a measure of contractility, namely the time it takes to build up enough force in the left ventricle after the start of electrical activity to open the aortic valves. Although this time is strongly dependent on noradrenergic effects on the ventricle, it is also sensitive to pre- and afterload. Effects of between-subject differences in pre- and afterload may be incompletely captured by the covariates MAP and HR. This limitation is balanced by strong points: this is the first longitudinal study with a large enough sample to separate antidepressant effects from those of the psychiatric condition per se, by including healthy controls and subjects with depressive and/or anxiety disorders not using antidepressants as well as subjects using different types of antidepressants. Previous studies were much smaller, simply excluded antidepressant users (Koschke et al, 2009; Light et al, 1998) or applied antidepressant washout periods before testing that may have been too short (10 day-2 weeks) (Esler et al, 1982; Guinjoan et al, 1995).

We conclude that SNRIs and TCAs, but not SSRIs exert detrimental effects on cardiac sympathetic control over time. These results converge with several studies reporting increased occurrence of hypertension, metabolic syndrome, and adverse cardiovascular events in patients using TCAs and SNRIs (Cohen et al, 2000; Tata et al, 2005; Degner et al, 2004; Licht et al, 2009b; Koschke et al, 2009; van Reedt Dortland et al, 2010). Also in earlier NESDA papers, we confirmed that TCAs and SNRIs did, but SSRIs did not, negatively impact on the occurrence of hypertension and metabolic syndrome (Licht et al, 2009b; van Reedt Dortland et al, 2010). The detrimental effects of TCAs and SNRIs on cardiac sympathetic regulation are alarming in view of the well-established relation between depression/anxiety and CVD. This may have consequences for the optimal pharmacological treatment of depressive and anxiety disorders, especially in patients already at increased risk for CVD. For these patients, SSRIs may be the drug of first choice because they do not yield the adverse increasing effect on cardiac sympathetic regulation that was observed for TCAs and SNRIs.

\section{ACKNOWLEDGEMENTS}

The infrastructure for the NESDA study (http://www. nesda.nl) is funded through the Geestkracht program of the Netherlands Organization for Health Research and Development (Zon-Mw, grant number 10-000-1002) and is supported by participating universities and mental healthcare organizations (VU University Medical Center, GGZ inGeest, Arkin, Leiden University Medical Center, GGZ 
Rivierduinen, University Medical Center Groningen, Lentis, GGZ Friesland, GGZ Drenthe, Scientific Institute for Quality of Healthcare (IQ healthcare), Netherlands Institute for Health Services Research (NIVEL) and Netherlands Institute of Mental Health and Addiction (Trimbos). Data analyses were supported by NWO grant (Vidi, 917.66.320) to Dr Penninx and an EMGO fellowship to Dr Licht.

\section{DISCLOSURE}

The authors declare no conflict of interest.

\section{REFERENCES}

Ahrens T, Deuschle M, Krumm B, van der PG, den Boer JA, Lederbogen $F$ (2008). Pituitary-adrenal and sympathetic nervous system responses to stress in women remitted from recurrent major depression. Psychosom Med 70: 461-467.

American Psychiatric Association (2001). Diagnostic and Statistical Manual of Mental Disorders, 4th edn, Washington.

Barton DA, Dawood T, Lambert EA, Esler MD, Haikerwal D, Brenchley C et al (2007). Sympathetic activity in major depressive disorder: identifying those at increased cardiac risk? J Hypertens 25: 2117-2124.

Berntson GG, Cacioppo JT, Binkley PF, Uchino BN, Quigley KS, Fieldstone A (1994). Autonomic cardiac control. III. Psychological stress and cardiac response in autonomic space as revealed by pharmacological blockades. Psychophysiology 31: 599-608.

Booth M (2000). Assessment of physical activity: an international perspective. Res Q Exerc Sport 71: S114-S120.

Bruno RL, Myers SJ, Glassman AH (1983). A correlational study of cardiovascular autonomic functioning and unipolar depression. Biol Psychiatry 18: 227-235.

Cacioppo JT, Berntson GG, Binkley PF, Quigley KS, Uchino BN, Fieldstone A (1994). Autonomic cardiac control. II. Noninvasive indices and basal response as revealed by autonomic blockades. Psychophysiology 31: 586-598.

Cohen J (1988). Statistical power analysis for the behavioral sciences 2nd (edn). Lawrence Earlbaurn Associates: Hillsdale, NJ.

Cohen HW, Gibson G, Alderman MH (2000). Excess risk of myocardial infarction in patients treated with antidepressant medications: association with use of tricyclic agents. Am J Med 108: 2-8.

Dawood T, Schlaich M, Brown A, Lambert G (2009). Depression and blood pressure control: all antidepressants are not the same. Hypertension 54: e1.

de Geus EJ, Willemsen GH, Klaver CH, van Doornen LJ (1995). Ambulatory measurement of respiratory sinus arrhythmia and respiration rate. Biol Psychol 41: 205-227.

Degner D, Grohmann R, Kropp S, Ruther E, Bender S, Engel RR et al (2004). Severe adverse drug reactions of antidepressants: results of the German multicenter drug surveillance program AMSP. Pharmacopsychiatry 37(Suppl 1): S39-S45.

Eaker ED, Sullivan LM, Kelly-Hayes M, D’Agostino Sr RB, Benjamin EJ (2005). Tension and anxiety and the prediction of the 10-year incidence of coronary heart disease, atrial fibrillation, and total mortality: the Framingham Offspring Study. Psychosom Med 67: 692-696.

Eckberg DL (2003). The human respiratory gate. J Physiol 548: 339-352.

Eisenhofer G, Friberg P, Rundqvist B, Quyyumi AA, Lambert G, Kaye DM et al (1996). Cardiac sympathetic nerve function in congestive heart failure. Circulation 93: 1667-1676.

Elam M, Thoren P, Svensson TH (1986). Locus coeruleus neurons and sympathetic nerves: activation by visceral afferents. Brain Res 375: 117-125.
Elam M, Yao T, Svensson TH, Thoren P (1984). Regulation of locus coeruleus neurons and splanchnic, sympathetic nerves by cardiovascular afferents. Brain Res 290: 281-287.

Esler M, Alvarenga M, Lambert G, Kaye D, Hastings J, Jennings G et al (2004). Cardiac sympathetic nerve biology and brain monoamine turnover in panic disorder. Ann NY Acad Sci 1018: 505-514.

Esler M, Straznicky N, Eikelis N, Masuo K, Lambert G, Lambert E (2006). Mechanisms of sympathetic activation in obesity-related hypertension. Hypertension 48: 787-796.

Esler M, Turbott J, Schwarz R, Leonard P, Bobik A, Skews H et al (1982). The peripheral kinetics of norepinephrine in depressive illness. Arch Gen Psychiatry 39: 295-300.

Flaa A, Aksnes TA, Kjeldsen SE, Eide I, Rostrup M (2008a). Increased sympathetic reactivity may predict insulin resistance: an 18-year follow-up study. Metabolism 57: 1422-1427.

Flaa A, Sandvik L, Kjeldsen SE, Eide IK, Rostrup M (2008b). Does sympathoadrenal activity predict changes in body fat? An 18-y follow-up study. Am J Clin Nutr 87: 1596-1601.

Glassman A (2008). Depression and cardiovascular disease. Pharmacopsychiatry 41: 221-225.

Gold PW, Wong ML, Goldstein DS, Gold HK, Ronsaville DS, Esler M et al (2005). Cardiac implications of increased arterial entry and reversible 24-h central and peripheral norepinephrine levels in melancholia. Proc Natl Acad Sci USA 102: 8303-8308.

Grant MM, Weiss JM (2001). Effects of chronic antidepressant drug administration and electroconvulsive shock on locus coeruleus electrophysiologic activity. Biol Psychiatry 49: 117-129.

Grossman P, van Beek J, Wientjes C (1990). A comparison of three quantification methods for estimation of respiratory sinus arrhythmia. Psychophysiology 27: 702-714.

Guinjoan SM, Bernabo JL, Cardinali DP (1995). Cardiovascular tests of autonomic function and sympathetic skin responses in patients with major depression. J Neurol Neurosurg Psychiatry 59: 299-302.

Harris WS, Schoenfeld CD, Weissler AM (1967). Effects of adrenergic receptor activation and blockade on the systolic preejection period, heart rate, and arterial pressure in man. J Clin Invest 46: 1704-1714.

Helke CJ, Capuano S, Tran N, Zhuo H (1997). Immunocytochemical studies of the 5 -HT(1A) receptor in ventral medullaryneurons that project to the intermediolateral cell column and contain serotonin or tyrosine hydroxylase immunoreactivity. J Comp Neurol 379: 261-270.

Houtveen JH, de Groot PF, de Geus EJ (2005). Effects of variation in posture and respiration on RSA and pre-ejection period 1. Psychophysiology 42: 713-719.

Howell C, Wilson AD, Waring WS (2007). Cardiovascular toxicity due to venlafaxine poisoning in adults: a review of 235 consecutive cases. Br J Clin Pharmacol 64: 192-197.

Koschke M, Boettger MK, Schulz S, Berger S, Terhaar J, Voss A et al (2009). Autonomy of autonomic dysfunction in major depression. Psychosom Med 71: 852-860.

Krzeminski K, Kruk B, Nazar K, Ziemba AW, Cybulski G, Niewiadomski W (2000). Cardiovascular, metabolic and plasma catecholamine responses to passive and active exercises. J Physiol Pharmacol 51: 267-278.

Lamers F, Hoogendoorn A, Smit JH, van Dyck R, Zitman FG, Nolen WA et al (2012). Socio-demographic and psychiatric determinants of attrition in the Netherlands Study of Depression and Anxiety (NESDA). Compr Psychiatry 53: 63-70.

Licht CMM, de Geus EJ, Penninx BWJH (2009a). Depression and blood pressure control: all antidepressants are not the same. Hypertension 54: e2.

Licht CMM, de Geus EJ, Seldenrijk A, van Hout HP, Zitman FG, van Dyck $\mathrm{R}$ et al (2009b). Depression is associated with decreased blood pressure, but antidepressant use increases the risk for hypertension. Hypertension 53: 631-638. 
Licht CMM, de Geus EJ, van Dyck R, Penninx BWJH (2009c). Association between anxiety disorders and heart rate variability in the Netherlands Study of Depression and Anxiety (NESDA). Psychosom Med 71: 508-518.

Licht CMM, de Geus EJ, van Dyck R, Penninx BWJH (2010). Longitudinal evidence for unfavorable effects of antidepressants on heart rate variability. Biol Psychiatry 68: 861-868.

Licht CMM, de Geus EJ, Zitman FG, Hoogendijk WJ, van Dyck R, Penninx BWJH (2008). Association between major depressive disorder and heart rate variability in the Netherlands Study of Depression and Anxiety (NESDA). Arch Gen Psychiatry 65: $1358-1367$.

Light KC, Kothandapani RV, Allen MT (1998). Enhanced cardiovascular and catecholamine responses in women with depressive symptoms. Int J Psychophysiol 28: 157-166.

Masuo K, Katsuya T, Fu Y, Rakugi H, Ogihara T, Tuck ML (2005). Beta2-adrenoceptor polymorphisms relate to insulin resistance and sympathetic overactivity as early markers of metabolic disease in nonobese, normotensive individuals. Am J Hypertens 18: $1009-1014$.

Masuo K, Rakugi H, Ogihara T, Esler MD, Lambert GW (2010). Cardiovascular and renal complications of type 2 diabetes in obesity: role of sympathetic nerve activity and insulin resistance. Curr Diabetes Rev 6: 58-67.

Mezzacappa ES, Kelsey RM, Katkin ES (1999). The effects of epinephrine administration on impedance cardiographic measures of cardiovascular function. Int J Psychophysiol 31: 189-196.

Miyamoto Y, Higuchi J, Abe Y, Hiura T, Nakazono Y, Mikami T (1983). Dynamics of cardiac output and systolic time intervals in supine and upright exercise. J Appl Physiol 55: 1674-1681.

Nalivaiko E (2006). 5-HT(1A) receptors in stress-induced cardiac changes: a possible link between mental and cardiac disorders. Clin Exp Pharmacol Physiol 33: 1259-1264.

Nelesen RA, Shaw R, Ziegler MG, Dimsdale JE (1999). Impedance cardiography-derived hemodynamic responses during baroreceptor testing with amyl nitrite and phenylephrine: a validity and reliability study. Psychophysiology 36: 105-108.

Newlin DB, Levenson RW (1979). Pre-ejection period: measuring beta-adrenergic influences upon the heart. Psychophysiology 16: 546-553.

Nicholson A, Kuper H, Hemingway H (2006). Depression as an aetiologic and prognostic factor in coronary heart disease: a meta-analysis of 6362 events among 146538 participants in 54 observational studies. Eur Heart J 27: 2763-2774.

Norton JM (2001). Toward consistent definitions for preload and afterload. Adv Physiol Educ 25: 53-61.

Penninx BWJH, Beekman AT, Honig A, Deeg DJ, Schoevers RA, van Eijk JT et al (2001). Depression and cardiac mortality: results from a community-based longitudinal study. Arch Gen Psychiatry 58: 221-227.

Penninx BWJH, Beekman AT, Smit JH, Zitman FG, Nolen WA, Spinhoven P et al (2008). The Netherlands Study of Depression and Anxiety (NESDA): rationale, objectives and methods. Int $J$ Methods Psychiatr Res 17: 121-140.

Roth WT, Doberenz S, Dietel A, Conrad A, Mueller A, Wollburg E et al (2008). Sympathetic activation in broadly defined generalized anxiety disorder. J Psychiatr Res 42: 205-212.

Roth WT, Telch MJ, Taylor CB, Agras WS (1988). Autonomic changes after treatment of agoraphobia with panic attacks. Psychiatry Res 24: 95-107.

Rush AJ, Gullion CM, Basco MR, Jarrett RB, Trivedi MH (1996). The Inventory of Depressive Symptomatology (IDS): psychometric properties. Psychol Med 26: 477-486.

Schachinger H, Weinbacher M, Kiss A, Ritz R, Langewitz W (2001). Cardiovascular indices of peripheral and central sympathetic activation. Psychosom Med 63: 788-796.
Sherwood A, Allen MT, Fahrenberg J, Kelsey RM, Lovallo WR, van Doornen LJ (1990). Methodological guidelines for impedance cardiography. Psychophysiology 27: 1-23.

Sherwood A, Allen MT, Obrist PA, Langer AW (1986). Evaluation of beta-adrenergic influences on cardiovascular and metabolic adjustments to physical and psychological stress. Psychophysiology 23: 89-104.

Shimizu S, Akiyama T, Kawada T, Shishido T, Mizuno M, Kamiya A et al (2010). In vivo direct monitoring of interstitial norepinephrine levels at the sinoatrial node. Auton Neurosci 152: 115-118.

Shores MM, Pascualy M, Lewis NL, Flatness D, Veith RC (2001). Short-term sertraline treatment suppresses sympathetic nervous system activity in healthy human subjects. Psychoneuroendocrinology 26: 433-439.

Smith JJ, Muzi M, Barney JA, Ceschi J, Hayes J, Ebert TJ (1989). Impedance-derived cardiac indices in supine and upright exercise. Ann Biomed Eng 17: 507-515.

Steer RA, Kumar G, Ranieri WF, Beck AT (1995). Use of the Beck Anxiety Inventory with adolescent psychiatric outpatients. Psychol Rep 76: 459-465.

Svedenhag J, Martinsson A, Ekblom B, Hjemdahl P (1986). Altered cardiovascular responsiveness to adrenaline in endurancetrained subjects. Acta Physiol Scand 126: 539-550.

Svensson TH (1987). Peripheral, autonomic regulation of locus coeruleus noradrenergic neurons in brain: putative implications for psychiatry and psychopharmacology. Psychopharmacology (Berl) 92: 1-7.

Tata LJ, West J, Smith C, Farrington P, Card T, Smeeth L et al (2005). General population based study of the impact of tricyclic and selective serotonin reuptake inhibitor antidepressants on the risk of acute myocardial infarction. Heart 91: 465-471.

van Reedt Dortland AK, Giltay EJ, van VT, Zitman FG, Penninx BW (2010). Metabolic syndrome abnormalities are associated with severity of anxiety and depression and with tricyclic antidepressant use. Acta Psychiatr Scand 122: 30-39.

Veith RC, Lewis N, Linares OA, Barnes RF, Raskind MA, Villacres EC et al (1994). Sympathetic nervous system activity in major depression. Basal and desipramine-induced alterations in plasma norepinephrine kinetics 5. Arch Gen Psychiatry 51: 411-422.

Veith RC, Raskind MA, Barnes RF, Gumbrecht G, Ritchie JL, Halter JB (1983). Tricyclic antidepressants and supine, standing, and exercise plasma norepinephrine levels. Clin Pharmacol Ther 33: 763-769.

Vincent S, Bieck PR, Garland EM, Loghin C, Bymaster FP, Black $\mathrm{BK}$ et al (2004). Clinical assessment of norepinephrine transporter blockade through biochemical and pharmacological profiles. Circulation 109: 3202-3207.

Weissler AM, Harris WS, Schoenfeld CD (1968). Systolic time intervals in heart failure in man. Circulation 37: 149-159.

Wilkinson DJ, Thompson JM, Lambert GW, Jennings GL, Schwarz RG, Jefferys D et al (1998). Sympathetic activity in patients with panic disorder at rest, under laboratory mental stress, and during panic attacks. Arch Gen Psychiatry 55: 511-520.

Willemsen GH, de Geus EJ, Klaver CH, van Doornen LJ, Carroll D (1996). Ambulatory monitoring of the impedance cardiogram. Psychophysiology 33: 184-193.

Winzer A, Ring C, Carroll D, Willemsen G, Drayson M, Kendall M (1999). Secretory immunoglobulin A and cardiovascular reactions to mental arithmetic, cold pressor, and exercise: effects of beta-adrenergic blockade. Psychophysiology 36: 591-601.

Wittchen HU (1994). Reliability and validity studies of the WHO-Composite International Diagnostic Interview (CIDI): a critical review. J Psychiatr Res 28: 57-84.

Wolf GK, Belz GG, Stauch M (1978). Systolic time intervalscorrection for heart rate. Basic Res Cardiol 73: 85-96.

World Health Organization Collaborating Centre for Drug Statistics Methodology (2010). Anatomical Therapeutic Chemical (ATC) classification. Available at: http://www.whocc.no/atcddd. 